\title{
Interferon- $\gamma$ and Interleukin-10 Gene Polymorphisms are not Predictors of Chronic Hepatitis C (Genotype-4) Disease Progression
}

\author{
Nermine Ahmed Bahgat ${ }^{1}$, Manal Mohamed Kamal ${ }^{1}$, Ashraf Omar Abdelaziz ${ }^{2}$, \\ Mohamed Ahmed Mohye ${ }^{2}$, Hend Ibrahim Shousha ${ }^{2 *}$, Mae Mohamed ahmed ${ }^{1}$, \\ Tamer Mahmoud Elbaz ${ }^{2}$, Mohamed Mahmoud Nabil ${ }^{2}$
}

\begin{abstract}
Immunoregulatory cytokines have an influence on hepatitis $\mathrm{C}$ virus (HCV) infection outcome. This study aimed to determine whether single nucleotide polymorphisms (SNP) in IFN- $\gamma$ and IL-10 genes are associated with susceptibility and/or are markers of prognosis regarding chronic hepatitis C outcomes. IFN $\gamma(+874 T / A)$ and IL-10 (-1082G/A) genotypes were determined in $75 \mathrm{HCV}$ genotype 4 patients with different disease severities (chronic hepatitis, $\mathbf{n = 2 5}$, liver cirrhosis and hepatocellular carcinoma $(\mathrm{HCC})$ on top of liver cirrhosis, $\mathbf{n = 5 0}$ ) and 25 healthy participants using allele-specific polymerase chain reaction. No statistical differences in allele or genotype distributions of IFN $\gamma$ and IL-10 genes were detected between patients and controls or between patientgroups. No significant difference in the frequency of IL-10 SNP at position -1082 or IFN- $\gamma$ at position +874T/A was found between chronic HCV genotype 4 and with progression of disease severity in liver cirrhosis or HCC. In conclusion; interferon- $\gamma$ and interleukin-10 gene polymorphisms are not predictors of disease progression in patients with chronic hepatitis $\mathrm{C}$ (Genotype-4).
\end{abstract}

Keywords: Chronic hepatitis C - single nucleotide polymorphism - IFN- $\gamma$ - IL-10 - HCV genotype 4

Asian Pac J Cancer Prev, 16 (12), 5025-5030

\section{Introduction}

Hepatitis C virus (HCV) is a major cause of a widespectrum of liver diseases ranging from chronichepatitis to cirrhosis and hepatocellular carcinoma (HCC).It infects almost 3\% of the world's population. Egypt has the highest prevalence of $\mathrm{HCV}$ worldwide (15\%) with genotype-4a accounting for almost $90 \%$ of infections (Guerra et al., 2012). Egypt has an estimated annual incidence of HCV about 150,000 cases (Galal et al., 2014).

The natural history of $\mathrm{HCV}$ is quite variable. In the majority of cases, neither the early innate immune response nor the adaptive immunity clears the virus and the infection becomes chronic. The ineffective inflammatory response drives fibrogenesis and the development of cirrhosis (Heydtmann et al., 2009). Factors promoting disease progression include: duration of infection, age at the time of infection, gender, alcohol consumption, immunosuppression (e.g. HIV co-infection or organ transplantation), obesity, insulin resistance, co-infection with other viruses and genetic factors (Al-Kubaisy et al., 2014). Once patients develop cirrhosis, HCC develops at approximately $1-4 \%$ per year and is increased in patients with raised $\alpha$-fetoprotein levels at baseline (Asahina et al., 2013). Cytokines form a regulatory network to directly or indirectly stimulate downstream signaling pathways in the occurence of malignancies (Duan et al., 2014). In addition to chronic inflammation and immune-mediated destruction of liver cells; also oxidative stress, apoptosis induced by HCV, DNA damage cause genomic aberrations and continuous hepatic regeneration that promotes HCC development within the $\mathrm{HCV}$ infected patients (Zekri et al., 2014).

CD4+T helper cell type 1 (Th1) and type 2(Th2) cytokines are the principal coordinators of the adaptive immune response against $\mathrm{HCV}$ via secreting antiviral cytokines and activating viral specific Bcells and CD8+T cells (Kaplan et al., 2007).The TH1 subtype is characterized by a cell-mediated immune response evoked by TH1- cytokines (IL-2, IL-12 and IFN- $\gamma$ ) and the TH2 subtype promotes a strong humoral response under the control of TH2-associated cytokines (IL-4, IL-6 and IL10) (Grakoui et al., 2003). Accordingly, it is supposed that the genetic variationsaffectingcytokine expression might influence chronic hepatitis C outcomes (Ollier, 2004). One 
of the most important Th 1 cytokines is IFN- $\gamma$. Significant correlation was observed between expression level of IFN- $\gamma$ mRNA and stage of fibrosis in chronic hepatitis C (Gigi et al., 2008); its level may interfere and affect the outcome of antiviral therapy (Sarvari et al., 2014). It has been established that the T-to-A polymorphism at position +874 of the first intron of IFN- $\gamma$ gene could directly influence IFN- $\gamma$ production level (Bouzgarrou et al., 2009). It was also concluded that heterogeneity at +2109 locus of IFN- $\gamma$ gene but not at +874 locus could interferewith successful therapy in patients infected with HCV genotype 1 (Sarvari et al., 2014).

Interleukin-10 (IL-10) is an immunoregulatory cytokine produced by Th2 cells, macrophages and regulatory T-cells. It is also produced by various cells in the liver including hepatocytes, sinusoidal endothelial cells, Kupffer cells, stellate cells, and liver-associated lymphocytes. It has anti-inflammatory activity by inhibiting the synthesis of cytokines such as IL-6, IL-8, IL-12, and TNF- $\alpha$ by activated macrophage and IFN- $\gamma$ by $\mathrm{T}$ cells. Its expression is downregulated in chronic HCV and may influence HCV infection susceptibility as well as spontaneous and treatment-induced viral eradication (Helal et al., 2014). The IL-10 promoter is highly polymorphic, and three SNPs -1082G/A, -819C/T, -592C/ A were associated with differential IL-10 expression (Bouzgarrou et al., 2009). This study aims to investigate whether single nucleotide polymorphismsin IFN- $\gamma$ and IL-10 genes are associated with susceptibility and/or are markers of prognosis to chronic hepatitis $\mathrm{C}$ outcomes.

\section{Materials and Methods}

This study was conducted on 75 HCV related chronic liver disease Egyptian patients from May 2012 to March 2014.Patients were assigned into: group I including 25 patients with chronic hepatitis $\mathrm{C}$ who were recruited from Endemic Medicine Department, school of medicine, Cairo University. All patients did not receive prior antiviral therapy. Group II including 50 patients: $25 \mathrm{HCC}$ patients attending the multidisciplinary $\mathrm{HCC}$ clinic, Faculty of medicine, Cairo University who did not receive prior therapy for $\mathrm{HCC}$ in addition to 25 patients with $\mathrm{HCV}$ related liver cirrhosis that were also recruited from Endemic Medicine Department, school of medicine, Cairo University. Group III included25 participants were selected randomly from healthy blood donors and enrolled as a control group. They were seronegative for $\mathrm{HCV}$ and HBV.

HCC was diagnosed according to the American Association for the Study of Liver Diseases (AASLD) updated practice guidelines (Bruix et al., 2011). Patients and controls were gender and age matched, and they were from the same geographical area. Approval for the study was given by the National Ethical Committee of Cairo University, and informed consent was obtained from each patient and control participant. Patients presenting with other causes of chronic hepatitis, testing positive for other hepatotropic viruses or treated with antiviral drugs were excluded.

All patients were subjected to Full history taking and clinical examination. The following investigations had been done: Complete liver \&kidney functions. Coagulation profile (Prothrombin Time\& Concentration) and complete blood picture.HCV antibodies by 3rd generation enzyme linked immunosorbant assay. HCV genotyping was done using reverse transcription polymerase chain reaction (RT-PCR) on applied biosystems TR Step One Real time PCR system.

\section{DNA extraction}

Peripheral blood $(5 \mathrm{ml})$ was collected in ethylenediaminetetraacetic acid (EDTA) tubes. Genomic DNA was extracted from peripheral leukocytes using the standard method (salting out procedure) (Miller et al., 1988) and stored at $-20^{\circ} \mathrm{C}$. Blood cells were mixed with Triton lysis buffer $(0.32 \mathrm{~mol} / \mathrm{l}$ sucrose, $1 \%$ Triton $\mathrm{X}-100,5 \mathrm{mmol} / \mathrm{l} \mathrm{MgCl} 2,10 \mathrm{mmol} / \mathrm{l}$ Tris-HCl, $\mathrm{pH} 7.5)$. Leukocytes were spun down and washed with sterilized $\mathrm{H}_{2} \mathrm{O}$. The pellet was incubated with proteinase $\mathrm{K}$ at $56 \mathrm{OC}$ and subsequently salted out at 4OC using a 5-mol/1 $\mathrm{NaCl}$ solution. Precipitated proteins were removed by centrifugation. DNA in the supernatant fluid was precipated with ethanol. The DNA pellet was dissolved in $400 \mathrm{ml}$ sterilized $\mathrm{H} 2 \mathrm{O}$ and stored at $-20^{\circ} \mathrm{C}$ until use.

IFN $\gamma(+874$ T/A) and IL-10 (- $1082 \mathrm{G} / \mathrm{A})$ genotyping:

Genotyping for polymorphism in IFN- $\gamma(+874 \mathrm{~T} / \mathrm{A})$ and IL-10 (-1082G/A) was carried out by the allele-specific PCR (AS-PCR) assay. For the genotyping of IFN $\gamma(+874 \mathrm{~T} / \mathrm{A})$, three primers described by Pravicaet al. were used (Pravica et al., 2000): 5' primers specific for IFN $\gamma+874 \mathrm{~T}$ (5'-TTCTTACAACACAAAATCAAATCT-3') or IFN $\gamma$ +874A (5'-TTCTTACAACACAAAATCAAATCA-3'), were separately mixed to a 3 ' common anti-sense primer (5'-TCAACAAAGCTGATACTCCA-3') under the following conditions: the reaction mixture was containing $5 \mu \mathrm{l}$ of genomic DNA, $5.5 \mu 1$ distilled water, $12.5 \mu 1$ master mix (TaqDNAq polymerase, buffer and $\mathrm{Mgcl} 2$ ), $1 \mu 1$ sense primer and $1 \mu \mathrm{l}$ common anti-sense primer. Two samples are available for each participant, one for each specific $\mathrm{T}$ or A allele of IFN- $\gamma$.

Amplification was performed using the thermal cycler (BiometraTE-3000, Germany) according to the following protocol: one cycle of $95^{\circ} \mathrm{C}$ for 1 minute followed by 10 cycles of $95^{\circ} \mathrm{C}$ c for 15 seconds, $62^{\circ} \mathrm{C}$ for 50 seconds, and $72^{\circ} \mathrm{C}$ for 40 seconds, then 20 cycles of $95^{\circ} \mathrm{C}$ for 20 seconds, $56^{\circ} \mathrm{C}$ for 50 seconds and $72^{\circ} \mathrm{C}$ for 50 seconds.

Similarly, primers described by Mullighanet al. were used to detect the G-to-A transition polymorphism at position -1082 of IL-10 gene (Mullighan et al., 1999). The specific primer sequences used were as follows: the 3' common anti-sense primer 5'-CAGTGCCAACTGAGAATTTGG-3'; theIL-101082G: 5'CTACTAAGGCTTCTTTGGGAG-3'; the IL10-1082A: 5'ACTACTANAGGCTTCTTTGGGAA-3'. All reactions were performed ina reaction mixture of $25 \mu \mathrm{l}$ volume containing $5 \mu \mathrm{l}$ of genomic DNA, $5.5 \mu \mathrm{l}$ distilled water, $12.5 \mu 1$ master mix (TaqDNAq polymerase, buffer and $\mathrm{Mgcl} 2), 1 \mu 1$ sense primer and $1 \mu 1$ common anti-sense primer. Two samples are available for each participant, one for each specific $\mathrm{G}$ or A allele of IL-10. Reaction conditions were as follows: $95^{\circ} \mathrm{C}$ for 3 minutes followed by 35 cycles 
at: $95^{\circ} \mathrm{C}$ for 45 seconds, $58^{\circ} \mathrm{C}$ for 40 seconds, $72^{\circ} \mathrm{C}$ for 1 minute with final extension at $72^{\circ} \mathrm{C}$ for 7 minutes. The amplified products were separated by electrophoresis on $1.5 \%$ agarose gel stained with ethidiumbromide. The gel was visualized under an ultraviolet trans-illuminator with a 100-base pair (bp) ladder (SIGMA chemical Co., Cairo, Egypt) and photographed.

\section{Statistical analysis}

The allele frequencies were tested for the HardyWeinberg equilibrium. The same test was used to evaluate any significant differences in the IFN- $\gamma$ and IL-10 allele/ genotype frequencies between patients and controls and among subgroups of patients (chronic hepatitis vs. LC/ HCC). Values of p_0.05 were considered statistically significant. Odds ratios (ORs) and $95 \%$ confidence intervals (CIs) were calculated to assess the relative disease risk conferred by a specific allele or genotype. Genotype frequencies of allele, genotype, and combined genotypes were compared among the groups by multivariate logistic regression analysis. Data were analyzed using the EpiInfo statistical program (version 5.01a-1991; Centers for Disease Control and Epidemiology Program office, Atlanta, GA). Multivariate analysis was made using SPSS 13.0 software (SPSS Inc., Chicago, IL).

\section{Results}

Our patients were divided according to the presence or absence of liver cirrhosis. The clinical and laboratory data of the different studied groups are shown in Table 1. Some statistical differences were observed between patients and controls in regard to age, bilirubin, albumin, AST, ALT, Hb and platelet count by univariate analysis.

IFN- $\gamma(+874$ T/A) and IL-10 (-1082 G/A) allelic and genotypic distribution

IFN- $\gamma$ and IL-10 allele and genotype frequencies in all samples are shown in Table 2. Genotype distributions in control subjects were consistent with Hardy-Weinberg equilibrium. No statistically significant differences were detected between patients and controls for both polymorphisms.

Genotype frequency analysis of IFN- $\gamma$ at position +874 between chronic hepatitis patients and LC/HCC; representing the progressing disease severity; showed a higher rate of TT, TA, AA and TT+TA genotypes in LC/HCC group than in chronic hepatitis although not statistically significant (Table 2). In addition, the IFN- $\gamma$ $874 \mathrm{~T}$ allele was found to be more frequent in patients with end-stage $\mathrm{HCV}$ than in patients with chronic hepatitis.

Table 1. Demographic, Clinical and Virological Factors of the Studied Population

\begin{tabular}{|c|c|c|c|c|c|}
\hline & & $\begin{array}{l}\mathrm{HCV} \\
(\mathrm{n}=25)\end{array}$ & $\begin{array}{c}\mathrm{LC} / \mathrm{HCC} \\
(\mathrm{n}=50)\end{array}$ & $\begin{array}{c}\text { Control } \\
(\mathrm{n}=25)\end{array}$ & $P$ value \\
\hline & Male & $17(0.68)$ & $41(0.84)$ & $18(0.72)$ & $0.67(\mathrm{NS})$ \\
\hline & Female & $6(0.32)$ & $9(0.16)$ & $7(0.28)$ & \\
\hline \multicolumn{2}{|c|}{ Age } & $46.32 \pm 4.66$ & $52.30 \pm 4.41$ & $44.60 \pm 5.18$ & 0.008 \\
\hline \multicolumn{2}{|c|}{ T.Bil. } & $0.75 \pm 0.11$ & $2.35 \pm 2.01$ & $0.83 \pm 0.13$ & 0.006 \\
\hline \multicolumn{2}{|c|}{ Albumin } & $4.38 \pm 0.37$ & $2.81 \pm 0.83$ & $3.86 \pm 1.15$ & 0.009 \\
\hline \multicolumn{2}{|c|}{ AST } & $61.88 \pm 64.29$ & $75.64 \pm 32.93$ & $21.40 \pm 5.33$ & 0.008 \\
\hline \multicolumn{2}{|c|}{ ALT } & $62.80 \pm 59.26$ & $48.08 \pm 22.34$ & $22.56 \pm 8.53$ & 0.007 \\
\hline \multicolumn{2}{|l|}{$\mathrm{Hb}$} & $14.20 \pm 1.46$ & $11.02 \pm 2.02$ & $11.89 \pm 0.89$ & 0.008 \\
\hline \multicolumn{2}{|c|}{ TLC } & $9.37 \pm 11.62$ & $4.53 \pm 2.38$ & $4.93 \pm 0.65$ & $0.05(\mathrm{NS})$ \\
\hline \multicolumn{2}{|c|}{ Plateles } & $208.56 \pm 59.18$ & $117.52 \pm 66.34$ & $210.88 \pm 49.18$ & 0.006 \\
\hline
\end{tabular}

Table 2. Differential Distribution of the IFN and IL10 Genotypes in Healthy Controls and Hepatitis C Virus (HCV) Patients at Different Stages of Chronic HCV Infection

\begin{tabular}{|c|c|c|c|c|c|c|c|c|}
\hline & $\begin{array}{l}\text { Control } \\
(\mathrm{n}=25)\end{array}$ & $\begin{array}{l}\text { Patients } \\
(\mathrm{n}=75)\end{array}$ & $\mathrm{OR}(95 \% \mathrm{CI})$ & $\mathrm{P}^{\mathrm{a}}$ & $\begin{array}{l}\text { Chronic hepatitis } \\
\qquad(\mathrm{n}=25)\end{array}$ & $\begin{array}{c}\mathrm{LC} / \mathrm{HCC} \\
(\mathrm{n}=50)\end{array}$ & OR $(95 \% \mathrm{CI})$ & $\mathrm{P}^{\mathrm{b}}$ \\
\hline \multicolumn{9}{|c|}{ Genotype IFN } \\
\hline TT & $4(0.16)$ & $21(0.28)$ & $1.97(0.47-8.2)$ & 0.35 & $5(0.20)$ & $16(0.32)$ & $1.92(0.46-8)$ & 0.37 \\
\hline TA & $15(0.60)$ & $38(0.51)$ & $0.95(0.3-2.9)$ & 0.92 & $14(0.56)$ & $24(0.48)$ & $1(0.31-3.44)$ & 1 \\
\hline AA & $6(0.24)$ & $16(0.21)$ & 1 & -- & $6(0.24)$ & $10(0.20)$ & 1 & -- \\
\hline $\mathrm{TT}+\mathrm{TA}$ & $19(0.40)$ & $59(0.79)$ & $1.2(0.4-3.4)$ & 0.77 & $19(0.76)$ & $40(0.80)$ & $1.26(0.4-3.99)$ & 0.69 \\
\hline \multicolumn{9}{|l|}{ Allele } \\
\hline $\mathrm{T}$ & 23 & 80 & $1.3(0.71-2.55)$ & 0.37 & 24 & 56 & $1.38(0.70-2.72)$ & 0.36 \\
\hline $\mathrm{A}$ & 27 & 70 & 1 & -- & 26 & 44 & 1 & -- \\
\hline \multicolumn{9}{|l|}{ Genotype } \\
\hline \multicolumn{9}{|l|}{ IL-10 } \\
\hline GG & $4(0.16)$ & $15(0.20)$ & $1.1(0.26-4.5)$ & 0.92 & $7(0.28)$ & $8(0.16)$ & $0.36(0.10-1.49)$ & 0.15 \\
\hline GA & $15(0.60)$ & $39(0.52)$ & $0.74(0.25-2.2)$ & 0.59 & $13(0.52)$ & $26(0.52)$ & $0.63(0.2-2.1)$ & 0.44 \\
\hline AA & $6(0.24)$ & $21(0.28)$ & 1 & -- & $5(0.20)$ & $16(0.32)$ & 1 & -- \\
\hline GG/GA & $21(0.84)$ & $54(0.72)$ & $0.81(0.29-2.3)$ & 0.56 & $20(0.80)$ & $34(0.68)$ & $0.53(0.17-1.7)$ & 0.28 \\
\hline \multicolumn{9}{|l|}{ Allele } \\
\hline $\mathrm{G}$ & 23 & 69 & $1(0.53-1.9)$ & 1 & 27 & 42 & $0.62(0.31-1.2)$ & 0.16 \\
\hline $\mathrm{A}$ & 27 & 81 & 1 & -- & 23 & 58 & 1 & \\
\hline
\end{tabular}

CI: confidence interval; HCC: Hepatocellular carcinoma in liver cirrhosis; OR: odds ratio; ${ }^{a}$ Patients vs. controls; ${ }^{\text {L Liver cirrhosis/ }}$ hepatocellular carcinoma ( $\mathrm{LC} / \mathrm{HCC})$ vs chronic hepatitis 
Table 3. Combined Effects of IFN and IL Polymorphisms between Controls and Patients and between Chronic Hepatitis and Cirrhosis /HCC

\begin{tabular}{|c|c|c|c|c|c|c|c|c|}
\hline & $\begin{array}{l}\text { Control } \\
(\mathrm{N}=25)\end{array}$ & $\begin{array}{l}\text { Patients } \\
(\mathrm{N}=75)\end{array}$ & $\mathrm{OR}(95 \% \mathrm{CI})$ & $\mathrm{P}^{\mathrm{a}}$ & $\begin{array}{l}\text { Chronic hepatitis } \\
\qquad(n=25)\end{array}$ & $\begin{array}{l}\mathrm{LC} / \mathrm{HCC} \\
(\mathrm{n}=50)\end{array}$ & $\mathrm{OR}(95 \% \mathrm{CI})$ & $\mathrm{P}^{\mathrm{b}}$ \\
\hline IFN-low/IL-10high & $4(0.16)$ & $15(0.20)$ & $1.3(0.3-6.2)$ & 0.72 & $6(0.24)$ & $9(0.18)$ & $2 \quad(0.5-8.5)$ & 0.35 \\
\hline IFN-high/IL-10high & $15(0.6)$ & $39(0.52)$ & $1.9(0.5-7)$ & 0.29 & $14(0.56)$ & $25(0.50)$ & $1.7(0.5-5.6)$ & 0.4 \\
\hline IFN-low/IL-10low & $2(0.08)$ & $1(0.01)$ & $10(0.7-138)$ & $0.049 *$ & $0(0)$ & $1(0.02)$ & NA & 0.57 \\
\hline IFN-high/IL-10low & $4(0.16)$ & $20(0.27)$ & 1 & -- & $5(0.20)$ & $15(0.30)$ & 1 & - \\
\hline
\end{tabular}

CI: confidence interval; HCC: Hepatocellular carcinoma in liver cirrhosis; LC: liver cirrhosis; OR: oddsratio; ${ }^{a}$ Patients vs. controls; ${ }^{b}$ Liver cirrhosis/ Hepatocellular carcinoma (LC/HCC) vs. chronic hepatitis; *Significant
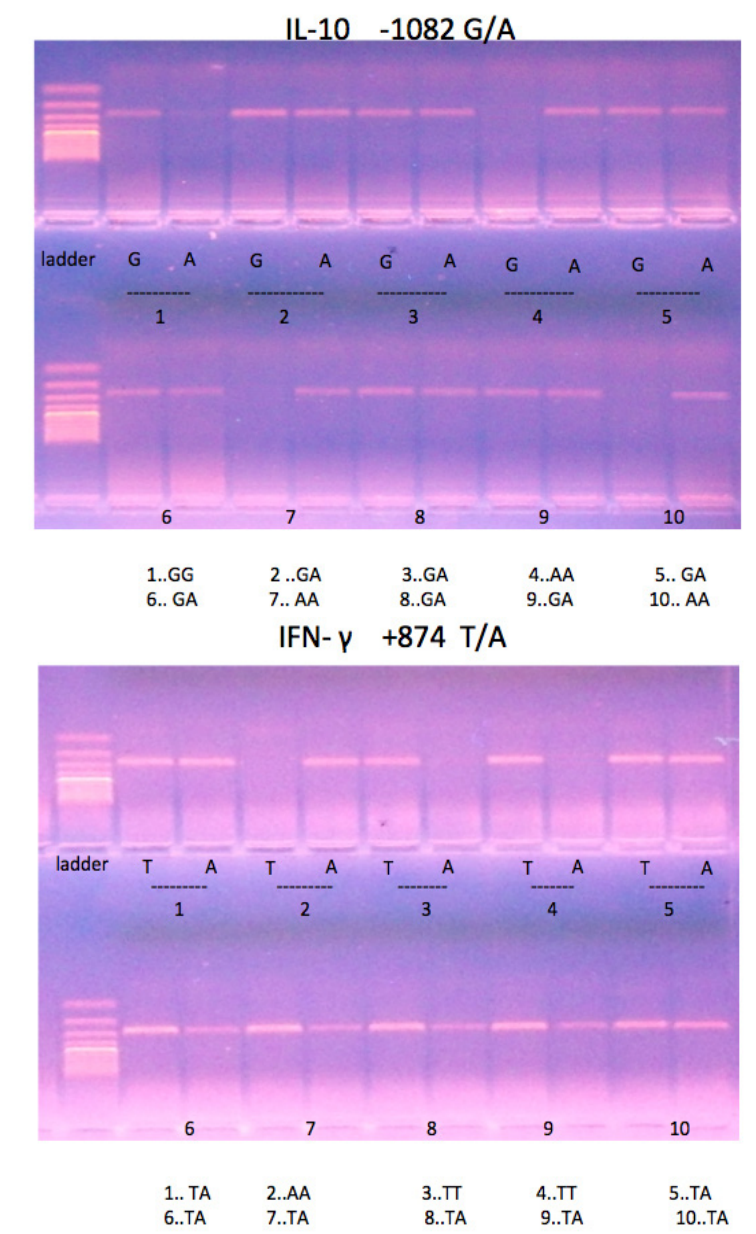

Figure 1. Agarose gel electrophoresis of AS-PCR products using (100 bp) ladder. each participant is presented by two lanes for, a) G and A IL10-1082 polymorphisms respectively, b) $\mathrm{T}$ and $\mathrm{A}$ IFN- $\boldsymbol{\gamma}+874$ polymorphisms respectively

When comparing allele and genotype frequencies of the IL-10 -1082, no significant differences between the two groups of patients were observed.

Combined effect of IFN- $\gamma(+874 T / A)$ and IL-10 (-1082G/ A) gene polymorphisms

Due to the inhibitory action of IL-10 on IFN- $\gamma$ synthesis, the effect of IFN- $\gamma$ and IL-10 combined genotypes on chronic hepatitis $\mathrm{C}$ genotype 4outcome was analyzed. Genotypes were grouped into high or low producer genotypes. For IFN- $\gamma:$ TT and TA genotypes at position +874 were considered as high producer genotypes. AA genotype was considered as a low producer genotype. For IL-10, GG and GA at position -1082 were grouped into high producer genotypes and AA genotype was regarded as a low producer genotype (Table 3).No statistically significant differences in IFN- $\gamma$ and IL-10 combined genotype distributions between patients with chronic hepatitis $\mathrm{C}$ and Patients with liver cirrhosis and HCC although it increased with disease progression.

\section{Discussion}

Host genetic factors have an impact on the clinical outcomes of HCV infection; however, the possible mechanisms remain unclear. The role of immunepathogenesis in chronic hepatitis $\mathrm{C}(\mathrm{CHC})$ leads to extensive exploration of patients' immunity particularly inflammatory cytokines (Chuang et al., 2009). A shift to Th1-type cytokines has been associated with an exacerbated necro-inflammatory activity and liver fibrosis. Hepatocytes necrosis resulting from chronic inflammation and subsequent regeneration enhances mutagenesis and proto-oncogene stimulation in the host cells, leading to HCC (Bouzgarrou et al., 2009). Cytokine gene single nucleotide polymorphisms (SNPs) are involved in the genesis and progression of HCC (Bei et al., 2014).

IFN- $\gamma$ was found to participate in the immune response involved in fibrogenesis. Several studies provide evidence that IFN- $\gamma$ has a distinct role in Th1-type cellular response leading to inflammation and liver fibrosis in HCVrelated chronic liver disease (Bouzgarrou et al., 2009). Combination of intra-tumoral natural killer cells and IFN- $\gamma$ was found to be a promising independent predictor for recurrence and survival in HCC (Xiao et al., 2013). Heterogeneity at +874 locusof IFN $-\gamma$ gene showed no association with response to antiviral therapy with any difference between responders and nonresponders.

In our study, there was no statistically significant differences in IFN- $\gamma(+874 \mathrm{~T} / \mathrm{A})$ genotype frequency between chronic hepatitis patients genotype 4and cirrhotic/ HCC group although they showed a higher rate of TT, TA, AA and TT+TA polymorphisms.

Findings regarding the associations between IFN- $\gamma$ (+874T/A) polymorphism and fibrosis in $\mathrm{HCV}$ are conflicting. Other studies also showed no significant relationships between IFN- $\gamma+874 \mathrm{~A} / \mathrm{T}$ allele frequencies and the clinical outcome of $\mathrm{HCV}$ infection and fibrosis or liver disease severity (Barrett et al., 2003, Abbas et al., 2005; Gao et al., 2010).

In contrast to our study, Dai et al. (2006) found that $\mathrm{T}$ allele of +874 IFN- $\gamma$ was an independent factor associated with cirrhosis indicating that inheritance of +847 IFN- $\gamma$ 
polymorphism is associated with the cirrhosis in patients with $\mathrm{CHC}$. This could be attributed to our different $\mathrm{HCV}$ genotype as $48.7 \%$ of their patients had HCV genotype 1 b.In addition they did not include HCC to complete the full spectrum of disease progression.

IL-10, whose secretion is regulated by monocytes and lymphocytes, has an important role in the pathogenesis of CHC infection (Helal et al., 2014). It is an antiinflammatory cytokine and immune response modulator that can influence $\mathrm{HCV}$ infection susceptibility as well as spontaneous and treatment-induced viraleradication. Moreover, it has anti-fibrotic properties and plays a role in liver disease progression (Swiątek et al., 2012).

In a review that summarized studies on the role of interleukin-10 gene polymorphisms (mainly promoter SNPs at positions $-1082(\mathrm{G} / \mathrm{A}),-819(\mathrm{C} / \mathrm{T})$ and $-592(\mathrm{C} / \mathrm{A})$ ) regarding susceptibility to $\mathrm{HCV}$ infection, course of $\mathrm{HCV}$ related liver disease (fibrosis, cirrhosis, hepatocellular carcinoma, ALT abnormalities), spontaneous viral clearance and antiviral treatment outcomes; it was found that it is difficult to determine the importance of IL-10 polymorphism as a predictor of clinical outcome of hepatitis $\mathrm{C}$ and response to anti-HCV therapy before its beginning. Thus, they recommended continuation of studies on interleukin-10 polymorphisms and identification of other possible predictive markers in $\mathrm{HCV}$ infection that has important practical implications and may contribute to reduce the scale of hepatitis $\mathrm{C}$ problem (Swiątek et al., 2012).

In our study, no significant difference in the genotype profile of IL-10 (-1082) was detected between chronic $\mathrm{HCV}$ (persistent infection) and the spectrum of the increasing severity of liver affection by HCV with liver cirrhosis and HCC. Similarly another study on HCV genotype-4 had the same results as ours (Helal et al., 2014) and other researchers on other genotypes also showed the same results (Kusumoto et al., 2006). Another study by $\mathrm{Wu}$ and colleagues from China confirmed the lack of association of IL10 and other gene polymorphisms with $\mathrm{HCC}$ recurrence after liver transplantation $(\mathrm{Wu}$ et al., 2013)

On the other hand, Knapp et al. (2003) studies revealed an association of the G/G genotype at position 1082 with persistent infection. This association was also confirmed in a study by Vidigal et al. (2002) but this was based on a comparison with healthy controls rather than participants with self-limiting HCV infection. Our study confirms the need of future investigations of host-pathogen interactions underlying the genotype specific clinical outcomes of chronic HCV infection. We have some limitations in our study including low patient number and controls. In conclusion; interferon- $\gamma$ and interleukin-10 gene polymorphisms are not predictors of disease progression in patients with chronic hepatitis C (Genotype-4).

\section{References}

Abbas Z, Moatter T, Hussainy A, Jafri W (2005). Effect of cytokine gene polymorphism on histological activity index, viral load and response to treatment in patients with chronic hepatitis C genotype 3. World J Gastroenterol, 11, 6656-61.

Al-Kubaisy WA, Obaid KJ, Noor NA, Ibrahim NS, Al-Azawi AA (2014). Hepatitis $C$ virus prevalence and genotyping among hepatocellular carcinoma patients in Baghdad. Asian Pac J Cancer Prev, 15, 7725-30.

Asahina Y, Tsuchiya K, Nishimura T, et al (2013). $\alpha$-fetoprotein levels after interferon therapy and risk of hepatocarcinogenesis in chronic hepatitis C. Hepatology, 58, 1253-62.

Barrett S, Collins M, Kenny C, et al (2003). Polymorphisms in tumour necrosis factor-alpha, transforming growth factorbeta, interleukin-10, interleukin-6, interferon-gamma, and outcome of hepatitis C virus infection. J Med Virol, 71, 212-8.

Bei CH, Bai H, Yu HP, et al (2014). Combined effects of six cytokine gene polymorphisms and SNP-SNP interactions on hepatocellular carcinoma risk in Southern Guangxi, China. Asian Pac J Cancer Prev, 15, 6961-7.

Bouzgarrou N, Hassen E, Farhat K, et al (2009). Combined analysis of interferon- $\gamma$ and interleukin-10 gene polymorphisms and chronic hepatitis $\mathrm{C}$ severity. Human Immunology, 230, 236-70.

Bruix J, Sherman M (2011). American association for the study of liver diseases. management of hepatocellular carcinoma: an update. Hepatology, 53, 1020-22.

Chuang JY, Yang SS, Lu YT, et al (2009). IL-10 promoter gene polymorphisms and sustained response to combination therapy in Taiwanese chronic hepatitis C patients. Dig Liver Dis, 41, 424-30.

Dai CY, Chuang WL, Hsieh MY, et al (2006). Polymorphism of interferon-gamma gene at position +874 and clinical characteristics of chronic hepatitis C. Transl Res, $\mathbf{1 4 8}$, 128-33.

Duan Y, Shi JN, Pan C, Chen HL, Zhang SZ (2014) Association between the interleukin-17A -197G >A (rs2275913) polymorphism and risk of digestive cancer. Asian Pac J Cancer Prev, 15, 9295-300.

Galal IF, Zakaria Z, Allam WR, et al (2014). Cross reactive cellular immune response to $\mathrm{HCV}$ genotype 1 and 4 antigens among genotype 4 exposed subjects. PLoS One, 9, 101264.

Gao QJ, Liu DW, Zhang SY, Jia M, Wu LH (2010). Association between IFN-gamma+874 polymorphisms and the clinical outcomes of hepatitis B and/or hepatitis $\mathrm{C}$ virus infection. Zhonghua Liu Xing Bing XueZaZhi, 31, 324-8.

Gigi E, Raptopoulou-Gigi M, et al (2008). Cytokine mRNA expression in hepatitis $\mathrm{C}$ virus infection: Th1 predominance in patients with chronic hepatitis $\mathrm{C}$ and Th1-Th2 cytokine profile in subjects with self-limited disease. $J$ Viral Hepat, 15, 145-54.

Grakoui A, Shoukry NH, Woollard DJ, et al (2003). HCV persistence and immune evasion in the absence of memory T-cell help. Science, 302, 659-62.

Guerra J, Garenne M, Mohamed MK, Fontanet A (2012). HCV burden of infection in Egypt: results from a nationwide survey. J Viral Hepat, 19, 560-7.

Helal SF, Gomaa HE, Thabet EH, Younan MA, HelmyNA (2014). Impact of IL-10 (-1082) promoter-single nucleotide polymorphism on the outcome of hepatitis $\mathrm{C}$ virus genotype 4 infection. Clin Med Insights Gastroenterol, 1, 19-24.

Heydtmann M, Adams DH (2009). Chemokines in the Immunopathogenesis of Hepatitis C Infection. Hepatology, 49, 676-88.

Kaplan DE, Sugimoto K, Newton K, et al (2007). Discordant role of CD4 T-cell response relative to neutralizing antibody and CD8 T-cell responses in acute hepatitis C. Gastroenterology, 132, 654-66.

Knapp S, Hennig BJ, Frodsham AJ, et al (2003). Interlleukin-10 promoter polymorphisms and the outcome of hepatitis $\mathrm{C}$ 
virus infection. Immunogenetics, 55, 362-9.

Kusumoto K, Uto H, Hayashi K, et al (2006). Interleukin-10 or tumor necrosis factor-alpha polymorphisms and the natural course of hepatitis $\mathrm{C}$ virus infection in a hyperendemic area of Japan. Cytokine, 34, 24-31.

Miller SA, Dykes DD, Polesky HF (1988). A simple salting out procedure for extracting DNA from human nucleated cells. Nucleic Acids Res, 16, 1215.

Mullighan CG, Marshall SE, Bunce M, Welsh KI (1999). Variation in immunoregulatory genes determines the clinical phenotype of common variable immunodeficiency. GenesImmun, 1, 137-48.

Ollier WE (2004). Cytokine genes and disease susceptibility. Cytokine, 28, 174-8.

Pravica V, Perrey C, Stevens A, LeeJ H, Hutchinson IV (2000). A single nucleotide polymorphism in the first intron of the human IFN gamma gene: Absolute correlation with a polymorphic CA microsatellite marker of high IFN gamma production. Hum Immunol, 61, 863-6.

Sarvari J, NorozianH, FattahiMR, PirbonyehN, Moattari A (2014). The role of interferon gamma gene polymorphism $(+874 \mathrm{~A} / \mathrm{T},+2109 \mathrm{~A} / \mathrm{G}$, and $-183 \mathrm{G} / \mathrm{T})$ in response to treatment among hepatitis $\mathrm{C}$ infected patients in fars province, Southern Iran. Hepat Mon, 14, 14476.

Swiątek BJ (2012). Is interleukin-10 gene polymorphism a predictive marker in HCV infection? Cytokine Growth Factor Rev, 23, 47-59.

Vidigal PG, Germer JJ, Zein NN (2002). Polymorphisms in the interleukin-10, tumor necrosis factor-alpha and transforming growth factor-beta 1 genes in chronic hepatitis $\mathrm{C}$ patients treated with interferon and ribavirin. J Hepatol, 36, 271-7.

Wu LM, Zhou L, Xu J, et al (2013). Lack of association between genetic polymorphisms in cytokine genes and tumor recurrence in patients with hepatocellular carcinoma undergoing transplantation. Hepatobiliary Pancreat Dis Int, 12, 54-9.

Xiao YS, Gao Q, Xu XN, et al (2013). Combination of intratumoral invariant natural killer $\mathrm{T}$ cells and interferongamma is associated with prognosis of hepatocellular carcinoma after curative resection. PLoS One, 8, 70345.

Zekri Ael-R, Nassar AA, El-Din El-Rouby MN, et al (2014). Disease progression from chronic hepatitis $\mathrm{C}$ to cirrhosis and hepatocellular carcinoma is associated with increasing DNA promoter methylation. Asian Pac J Cancer Prev, 14, 6721-6. 